DOCTRINA

\title{
Por un abordaje crítico del impacto de las decisiones del sistema interamericano de derechos humanos
}

\author{
For a critical approach to the impact of the decisions \\ of the Inter-American Human Rights System
}

\author{
Daniel Cerqueira \\ Due Process of Law Foundation, Estados Unidos
}

\begin{abstract}
RESUMEN El presente artículo aborda la importancia de analizar el impacto del sistema interamericano de derechos humanos (SIDH) a partir de una metodología que permita distinguir las decisiones que implican un avance jurisprudencial genuino de aquellas que poseen un impacto bajo o meramente retórico para el derecho interamericano. Para ello, se adopta una definición de impacto más allá del cumplimiento de las medidas de reparación en un caso concreto, centrándonos en la capacidad del SIDH de generar un consenso mínimo sobre el alcance de las obligaciones de los Estados. En esa línea, se explica que la eficacia del SIDH radica en el potencial de crear nuevos parámetros de actuación estatal a partir de las decisiones de los órganos interamericanos. Finalmente, el artículo propone algunos criterios para medir la intensidad del impacto de los pronunciamientos de la Comisión y de la Corte Interamericana y describe algunas decisiones a partir de los referidos criterios.
\end{abstract}

PALABRAS CLAVE Sistema interamericano de derechos humanos, impacto, control de convencionalidad.

ABSTRACT This article addresses the importance of analyzing the impact of the InterAmerican Human Rights System (IAHRS) based on a methodology that distinguishes decisions that imply a genuine jurisprudential advance from those that entail a lower impact or one that is merely rhetorical with regards to the «Inter-American Law». To this end, we define impact beyond the compliance with reparation measures in a concrete complaint, focusing on the IAHRS capacity to generate a minimum consensus on the scope of the States' obligations. The article maintains that the effectiveness of the IAHRS lies in the potential to create new parameters for states action derived from the decisions of the inter-American organs. Finally, it proposes some criteria to measure the intensity of the impact of the pronouncements of the Inter-American Commission and Court and it describes some decisions based on said criteria. 
KEYWORDS Inter-American Human Rights System, impact, conventionality control.

\section{Introducción}

Pese al bajo grado de cumplimiento de las decisiones de los órganos del sistema interamericano de derechos humanos (SIDH), es innegable su impacto en la jurisprudencia de los tribunales domésticos, en los procesos legislativos y en el diseño de políticas públicas por parte de los Estados del continente. El contraste entre un bajo grado cumplimiento y un sólido potencial de impacto es inherente a los sistemas jurídicos conformados por órganos que carecen de herramientas coercitivas para asegurar la ejecución de sus fallos, como ocurre con la Comisión (CIDH), la Corte Interamericana (Corte IDH) y, en general, cualquier organismo supranacional de derechos humanos.

Son varios los y las autoras que se apartan de la comprensión de la eficacia del derecho internacional a partir de la correlación entre las decisiones de los órganos internacionales de adjudicación de un determinado sistema normativo y su cumplimiento por parte de los Estados, destinatarios de tales decisiones. Para algunos autores, el propio concepto de cumplimiento, entendido como regla de observancia, es inadecuado para entender cómo el derecho internacional ejerce efectos normativos (Howse y Taitel, 2010: 128-133).

Pese a la abundante literatura que recoge ejemplos de impacto del SIDH, no hay claridad en la doctrina y tampoco en los mensajes institucionales de la CIDH y de la Corte IDH sobre a qué se refieren exactamente cuando emplean la referida expresión. En ocasiones, «impacto del SIDH» es descrito a partir del convencionalismo lingüístico. Es decir, las decisiones del SIDH generan impacto pues poseen alguna repercusión para las víctimas del caso decidido, para el Estado denunciado y para la comunidad jurídica interamericana. Lato sensu, cualquier pronunciamiento de los órganos del SIDH, incluso en el marco del pilar de monitoreo y promoción, posee algún impacto jurídico, político y social. ${ }^{1}$

1. A los fines de este ensayo, el pilar de protección del SIDH abarca la facultad de sus órganos de pronunciarse sobre peticiones, casos y solicitudes de medidas de urgencia (cautelares y provisionales). Monitoreo se refiere a la supervisión que la CIDH lleva a cabo a través de los informes de países y temáticos, visitas in loco y de trabajo, comunicados de prensa, audiencias temáticas, solicitudes de información a los Estados, por medio de su Informe anual u otros tipos de pronunciamiento de carácter general. Por último, el pilar de promoción abarca los informes temáticos, las capacitaciones, los programas de perfeccionamiento profesional y otras iniciativas de diseminación de los estándares interamericanos. Las expresiones monitoreo, promoción y protección guardan relación con las atribuciones y facultades de la CIDH, definidas en su Plan Estratégico 2011-2015, bajo los términos «sistema de petición individual, monitoreo de la situación de los derechos humanos en los Estados miembros, y atención a líneas temáti- 
Ahora bien, sostener el impacto de todo y cualquier pronunciamiento del SIDH es un ejercicio tautológico que trivializa la importancia de distinguir el grado de impacto de una decisión en comparación con otra. Dicha distinción cobra aún más relevancia cuando la decisión examinada se fundamenta en un razonamiento jurídico o deslinda medidas de reparaciones distintas a los empleados en decisiones anteriores sobre los mismos supuestos fácticos. Como punto de partida, nos parece importante enfatizar que el impacto del pronunciamiento de un órgano de adjudicación del derecho descansa en su potencial de reforzar el consenso sobre cuáles son las reglas y principios que integran el derecho aplicable a la controversia decidida y en la capacidad de modificar una relación jurídica entre sujetos de derechos y destinatarios de los estándares plasmados en dichas reglas y principios.

El presente artículo propone un abordaje crítico del impacto del SIDH, más allá del cumplimiento de decisiones de sus órganos sobre casos contenciosos, a partir del análisis de algunos indicadores que permiten definir diferentes intensidades de impacto de una determinada decisión. La primera sección desarrolla, a la luz de algunos elementos de la filosofía del derecho, la diferencia conceptual entre cumplimiento de decisiones y su impacto jurídico. La segunda sección describe algunos criterios para evaluar el impacto de una decisión, a partir de la intensidad con la que se genera una nueva obligación estatal (intensidad acentuada), se amplía el alcance de un derecho previamente reconocido (intensidad moderada) o es intranscendente a tal efecto (baja intensidad).

La tercera sección describe algunas decisiones de los órganos del SIDH a partir de la referida tipología. Finalmente, el artículo hace un llamado a los usuarios del SIDH y a sus órganos para que se avance hacia un abordaje más crítico y menos autorreferencial del impacto de las decisiones de la Comisión y de la Corte IDH.

\section{La eficacia del SIDH: Diferencia conceptual entre impacto y cumplimiento de decisiones}

En sus informes anuales, la Corte IDH suele enfatizar los desafíos vinculados al bajo grado de cumplimiento de sus sentencias, destacando la importancia de que las instituciones nacionales de derechos humanos, las cortes nacionales, la academia y las organizaciones de la sociedad civil se involucren en el cumplimiento de las medidas de reparación dispuestas en sus fallos (Corte IDH, 2018: 83-85). A su vez, la CIDH ha establecido, desde su primer Plan Estratégico para el período 2011-2015, el cometido

cas prioritarias». En su plan estratégico para el quinquenio 2017-2021, la CIDH se refirió a sus pilares de trabajo de la siguiente forma: i) sistema de peticiones y casos; ii) monitoreo de la situación de derechos humanos en los Estados miembros; y iii) actividades de promoción y cooperación técnica. Véase CIDH (2017: 9). 
de «fomentar el pleno cumplimiento de sus pronunciamientos y recomendaciones», como una de sus prioridades (CIDH, 2011a: 40). Su último Plan Estratégico, relativo al período 2017-2022, contempla 20 programas de trabajo, los cuales se integran de forma trasversal a un «Programa Especial de Seguimiento de las Recomendaciones» (CIDH, 2017: 62).

En el ámbito doctrinario, existen varios estudios que demuestran el bajo grado de cumplimiento de las decisiones del SIDH. Algunos se basan en un análisis cuantitativo que indica un nivel particularmente bajo de cumplimiento de las reparaciones vinculadas a la obligación de investigar y sancionar violaciones de derechos humanos (Basch y otros, 2010: 18-21). En tanto sistema destinado a proveer justicia en casos concretos, el SIDH es, por lo tanto, deficiente no solo por la incapacidad de brindar respuestas oportunas a las víctimas (Sánchez, 2021: 29), sino por el elevado grado de incumplimiento de las reparaciones dictadas por sus órganos (Krsticevic, 2016: 9).

Pese a esta constatación ampliamente documentada (Open Society Justice Initiative, 2010: cap. 2), es importante distinguir los conceptos de cumplimiento de decisiones de los órganos del SIDH y su impacto. Mientras el primero guarda relación con la consecución de medidas de reparación, el segundo se refiere a la capacidad del SIDH de generar estándares jurídicos y lograr que sean observados por los órganos de los Estados parte.

En el ámbito del derecho internacional público, la doctrina especializada suele distinguir los siguientes conceptos: i) cumplimiento (compliance) o conformidad del comportamiento de un Estado con una regla jurídica internacional; ii) implementación, entendida como el proceso mediante el cual un Estado busca materializar un compromiso internacional; y iii) ejecución (enforcement), alusivo a las actividades de los Estados o de los órganos de adjudicación internacional, destinadas a persuadir un determinado Estado a observar la obligación pactada (Raustiala y Slaughter, 2002: 539). En el ámbito más específico del derecho internacional de los derechos humanos, los referidos conceptos poseen una connotación distinta, pues no hay una coincidencia entre los sujetos de derechos (individuos) y los destinatarios de la obligación internacional (Estados). Por otro lado, a diferencia de otras ramas del derecho internacional en que opera una relación entre Estados soberanos, en el derecho internacional de los derechos humanos se da una interacción más compleja entre órganos de adjudicación y monitoreo de obligaciones - por ejemplo, Corte IDH y CIDH, en el caso del SIDH, y Consejo de Derechos Humanos de la ONU y organismos cuasijudiciales en materia de derechos humanos, en el caso del sistema universal- $\mathrm{y}$ órganos internos de los Estados parte del sistema jurídico internacional respectivo, con competencia para interpretar y aplicar las reglas y ejecutar los fallos emanados de dicho sistema.

Para poder avanzar en esta discusión, es necesario aclarar a qué nos referimos cuando empleamos la expresión estándares interamericanos. La etimología de la pa- 
labra estándar remite a su homóloga standard en inglés, cuyo significado abarca una acción o comportamiento exigible a la luz de una obligación. La doctrina define estándares interamericanos como "pautas de comportamiento de los Estados parte en la Convención, como criterios de evaluación del mismo comportamiento y como reglas jurídicas, cuyo contenido implica el establecimiento de obligaciones concretas a cargo de los Estados, cuya inobservancia acarrea consecuencias en materia de responsabilidad internacional» (Ramírez, 2009: 28).

Los estándares interamericanos provienen, en primer lugar, de las obligaciones contenidas en la Convención Americana sobre Derechos Humanos (CADH) y en los demás instrumentos que conforman el marco normativo del SIDH. En léxico kelseniano, tales instrumentos establecen reglas primarias de conducta, cuya inobservancia da lugar a una sanción. ${ }^{2}$ Su teoría pura del derecho resalta la diferencia entre validez y eficacia de una norma jurídica. Mientras el primero significa que los destinatarios de la norma deben seguir la conducta prescrita, el segundo se refiere a la conformidad real de sus comportamientos con lo estatuido en la norma. En otras palabras, validez tiene que ver con la existencia de obligaciones jurídicas y eficacia con la conformidad entre tales obligaciones y el comportamiento de sus destinatarios. En términos kelsenianos, el SIDH carece de eficacia, pues la inobservancia de las obligaciones prescritas en las reglas primarias por parte de sus destinatarios (Estados parte) es una constante y las sanciones impuestas por los órganos de adjudicación de tales obligaciones (Corte IDH y CIDH) son asiduamente incumplidas.

En oposición a Kelsen, Herbert L. A. Hart se aparta de la centralidad de las llamadas reglas primarias, dirigidas a prescribir conductas y sancionar su infracción, y pone énfasis en las reglas secundarias de competencia (creación del derecho), adjudicación (aplicación del derecho) y reconocimiento (pertenencia o no de una norma a un determinado sistema legal). Para Hart, uno de los objetivos de cualquier sistema legal es la conformidad del comportamiento de los destinatarios de las reglas primarias con las conductas allí prescritas. Sin embargo, la eficacia del sistema depende más bien de la existencia de un consenso mínimo sobre el contenido de las normas secundarias por parte de los operadores del derecho; es decir, las personas, órganos y entidades de cuya conducta depende la comprensión sobre el contenido de las reglas secundarias (Hart, 1961: cap. 5).

Sin ánimo de trivializar la profundidad de la obra de los dos principales autores del positivismo jurídico, nuestra intención es traer algunas de sus proposiciones

2. Según Kelsen, la definición de derecho, entendido como un sistema legal, abarca «un orden coactivo de la conducta humana, presupuesto como soberano; cuando enlaza ciertos hechos que él determina, como condiciones de actos coactivos por él determinados». Para el autor, el derecho internacional se ajusta a dicha definición, por cuanto estatuye sanciones específicas para conductas que se apartan de la disposición normativa (Kelsen, 1967: cap. 7). 
al análisis de la eficacia del derecho interamericano, aquí definido como las reglas y principios derivados de los instrumentos interamericanos, cuyo contenido se complementa con los pronunciamientos de la CIDH y de la Corte IDH. La elección, por cierto, alegórica, de algunos elementos teóricos propios del iuspositivismo es deliberada, pues otras escuelas de la filosofía del derecho, como el iusnaturalismo y las corrientes neoconstitucionales contemporáneas, se centran mucho menos en el examen de la eficacia del derecho y más en la indagación sobre su fundamento axiológico o en las premisas bajo las cuales debe ser interpretado (Pozzolo, 1998).

Dicho lo anterior, la vinculación entre eficacia del SIDH y el cumplimiento de las decisiones de sus órganos proyecta una máxima kelseniana, en que la certeza de la sanción frente a conductas que infringen las reglas primarias es el indicador primordial. En un abordaje hartiano, el principal indicador debería ser la existencia de un consenso mínimo sobre el contenido de las reglas primarias (entiéndase, obligaciones estatales derivadas de los instrumentos interamericanos) y secundarias (a través de las cuales las obligaciones estatales son producidas y adjudicadas).

La siguiente sección desarrolla algunos criterios para evaluar el impacto de las decisiones del SIDH. Tales criterios siguen la concepción hartiana de eficacia del derecho interamericano, a saber: el potencial de coadyuvar en la definición de los parámetros de actuación estatal frente a un determinado supuesto fáctico, y en su capacidad para proyectar un consenso mínimo entre los operadores del $\mathrm{SIDH}^{3}$ sobre el contenido y exigibilidad de las obligaciones estatales.

\section{Criterios para evaluar el grado de impacto de una decisión del SIDH}

Mientras abundan ensayos académicos sobre la manera en que las decisiones del SIDH han influenciado la producción legislativa y adjudicación de controversias por parte de órganos internos de los Estados, son pocos los estudios sobre el impacto de tales decisiones en la modificación de fenómenos sociales que subyacen las violaciones de derechos humanos. En rigor, el impacto de la decisión de un órgano judicial o cuasijudicial - como es el caso de la $\mathrm{CIDH}$ - en la realidad social en la que interactúan los sujetos de derecho y destinatarios de una obligación ${ }^{4}$ trasciende la ciencia del derecho, ubicándose, más bien, en la esfera de la sociología jurídica. Lejos de aventurarse en una metodología inherente a esta disciplina, este artículo busca contribuir a un abordaje crítico del impacto de las decisiones del SIDH en términos estrictamente normativos.

3. Por operadores del SIDH, nos referimos a sus órganos de adjudicación (CIDH y Corte IDH), Estados, usuarios, tribunales internos y órganos estatales a cargo de llevar a cabo un control de convencionalidad.

4. En el caso del SIDH, los sujetos son toda persona sujeta a la jurisdicción de los Estados parte y los destinatarios son los propios Estados. 
Desde luego, compartimos la opinión según la cual toda decisión que reconoce la violación de derechos humanos y dispone medidas de reparación conlleva a un impacto positivo para las víctimas del caso y, en general, para el derecho interamericano (Corzo Sosa, 2013: 273-274). Pero, como ha sido mencionado previamente, nos interesa evaluar el impacto de las decisiones de los órganos del SIDH al margen del cumplimiento de las medidas de reparación en un caso concreto. En ese orden de ideas, un examen más detenido del impacto jurídico-normativo de una determinada decisión pasa por discernir cuándo esta establece un nuevo estándar jurídico, se limita a reproducir un estándar preexistente o contiene una regla jurisprudencial regresiva frente a un estándar anterior.

La premisa fundamental asumida en este artículo es que, en tanto fuente de estándares jurídicos, el impacto del SIDH es demostrable por el potencial de influenciar la comprensión misma del derecho interamericano por parte de sus operadores. Bajo esta óptica, una decisión tendrá mayor impacto cuando provea a tales operadores, sobre todo en el ámbito interno de los Estados, los elementos necesarios para definir cuál es el estándar aplicable a una determinada controversia y cuáles son las obligaciones que de él se derivan.

La próxima sección describe algunas decisiones de la CIDH y de la Corte IDH a partir de tres categorías de impacto: acentuado, moderado y bajo, definidas según el potencial de generar, reafirmar o reducir el alcance de una determinada obligación estatal.

\section{Ejemplos de decisiones de los órganos del SIDH e intensidad de su impacto}

Antes de comentar algunas decisiones de los órganos del SIDH, reconocemos el alcance acotado de los indicadores de intensidad de impacto basados exclusivamente en la creación, reafirmación o restricción de una determinada obligación estatal. Dichos indicadores no permiten evaluar, por ejemplo, el rigor argumentativo sobre los cuales se basan el estándar jurídico en cuestión. Estamos convencidos de que los criterios argumentativos endebles o irrazonables no son los mejores ingredientes para confeccionar un estándar jurídico. En cualquier caso, las secciones siguientes no constituyen una auditoría argumentativa de decisiones del SIDH, sino un ejercicio enunciativo de la intensidad de su impacto para el derecho interamericano.

De igual manera, la metodología aquí empleada no abarca una categoría de impacto relacionada con decisiones que, si bien no crean, reproducen, ni modifican obligaciones estatales, favorecen el acceso a la justicia interamericana para las víctimas de violaciones de derechos humanos. Es el caso, por ejemplo, de fallos que amplían la competencia temporal de los órganos del SIDH para conocer los efectos continuados de ciertas violaciones de derechos humanos; que flexibilizan el estándar probatorio o 
trasladan la carga de la evidencia al Estado con relación a ciertas controversias sobre hechos probados; o que eximen a familiares de víctimas directas de acreditar el daño inmaterial padecido en el carácter de víctimas indirectas, ${ }^{5}$ entre otras. Aunque ese tipo de situación escapa a los indicadores aquí empleados, es evidente que la ampliación de las reglas de adjudicación y de competencia de los órganos del SIDH posee un impacto positivo para el derecho interamericano.

Finalmente, destacamos que los informes de la CIDH y sentencias de la Corte IDH citados más adelante son meramente ejemplificativos de un universo mucho más amplio de decisiones que podrían ser del mismo modo catalogadas con base en la tipología de intensidad de impacto.

\section{Intensidad acentuada}

Las decisiones que se ubican en esta categoría son las que derivan una obligación estatal concreta de los instrumentos que conforman el SIDH, estableciendo así un nuevo parámetro de actuación estatal frente a un determinado supuesto fáctico. Entre las más consagradas se encuentran aquellas relacionadas con la obligación de investigar y sancionar graves violaciones de derechos humanos y, en particular, la prohibición de las leyes de amnistía frente a ese tipo de actos. La sentencia que inauguró dicha prohibición (Barrios Altos con Perú) sigue en etapa de cumplimiento y, periódicamente, la Corte IDH es llamada a decidir sobre medidas adoptadas por instancias del Estado peruano que incumplen las medidas de reparación. ${ }^{6}$ Ello demuestra, una vez más, que la ausencia de un cumplimiento integral de las medidas de reparación no es un elemento determinante en el examen del impacto jurídico-normativo de la decisión.

Con los años, la Corte IDH amplió la regla de Barrios Altos (circunscrita a la prohibición a leyes de amnistía) y estableció que los Estados parte del SIDH están obligados a «abstenerse de recurrir a figuras como la amnistía, el indulto, la prescripción y el establecimiento de excluyentes de responsabilidad, así como medidas que pretendan impedir la persecución penal o suprimir los efectos de una sentencia con-

5. Desde el caso Villagrán Morales y Otros (Niños de la Calle) con Guatemala, la Corte IDH ha reconocido como víctimas indirectas de la violación del derecho a la integridad personal (artículo 5 de la $\mathrm{CADH}$ ) a los familiares en primer grado de la víctima directa en casos relacionados con graves violaciones de derechos humanos. Dicha posición se consolidó en el caso Bámaca Velásquez con Guatemala y, con el tiempo, la Corte IDH eximió a dichos familiares de la carga de demonstrar el daño inmaterial sufrido, y concluyó que les era debida una compensación por derecho propio cuando el Estado denunciado es declarado responsable. Véase sentencia del caso Bámaca Velásquez con Guatemala, Corte Interamericana de Derechos Humanos, serie C núm. 70, fondo, 25 de noviembre de 200o, fojas 163-165.

6. Caso Barrios Altos y Caso La Cantuta con Perú, Corte Interamericana de Derechos Humanos, resolución de supervisión de cumplimiento de sentencia del 30 de mayo de 2018. 
denatoria frente a graves violaciones de derechos humanos». ${ }^{7}$ El estándar desarrollado en tales sentencias es una suerte de obra maestra del SIDH, al haber influenciado un sinnúmero de pronunciamientos de tribunales domésticos que, bajo la figura del control de convencionalidad, han limitado el alcance o derogado leyes que favorecen la impunidad en torno a graves violaciones de derechos humanos. ${ }^{8}$

Al margen de la constatación ampliamente documentada sobre cómo el referido estándar ha sido incorporado al ordenamiento de varios Estados, nos interesa resaltar que las decisiones de la Corte IDH sobre la materia, desde Barrios Altos en adelante, crean una nueva obligación estatal y, en un ejercicio de integración pro persona entre el derecho interno e interamericano, amplían el goce de los derechos humanos por parte de los individuos sometidos a la jurisdicción de los Estados parte de la CADH.

Otras decisiones que comparten esta estructura (crean un nuevo estándar jurídico) tienen que ver con la exclusión de la competencia de la jurisdicción militar para conocer violaciones de derechos humanos y para juzgar a civiles. Desde el primer fallo sobre el tema (Castillo Petruzzi y otros con Perú), ${ }^{9}$ la Corte IDH ha reiterado la obligación de restringir el foro militar a la protección de intereses jurídicos vinculados a las funciones propias de las Fuerzas Armadas. En un conjunto de sentencias iniciada con el caso Durand y Ugarte con Perú, ${ }^{10}$ el tribunal interamericano ha establecido que, so pena de violarse el principio de independencia e imparcialidad judicial, corresponde a la justicia ordinaria investigar, juzgar y sancionar violaciones de derechos humanos.

Nuevamente, pese a que la mayoría de los fallos relacionados a la limitación de la competencia del foro militar siguen en etapa de cumplimiento, sobran ejemplos de reformas de Códigos de Procedimiento Militar, leyes y jurisprudencia en la materia, producidas al amparo de los estándares interamericanos (Soto Muñoz, 2017: 181-186). En consonancia con los criterios aquí empleados, dichas decisiones poseen un impacto acentuado, pues establecen un estándar jurídico hasta entonces inexistente, el cual debe ser observado por los operadores jurídicos de los Estados parte de la $\mathrm{CADH}$ al momento de armonizarse su ordenamiento interno con el derecho interamericano.

Cabe destacar que, en los ejemplos aquí mencionados, el impacto de las sentencias de la Corte IDH son parte de un proceso más complejo, en que la CIDH suele

7. Véase, por ejemplo, sentencia del caso Gutiérrez Soler con Colombia, Corte Interamericana de Derechos Humanos, serie C núm. 132, fondo, 12 de septiembre de 2005, foja 97.

8. Véase, por ejemplo, Parra (2012) y DPLF (2009).

9. Sentencia del caso Castillo Petruzzi y otros con Perú, Corte Interamericana de Derechos Humanos, serie C núm. 52, fondo, 30 de mayo de 1999, foja 128.

10. Sentencia del caso Durand y Ugarte con Perú, Corte Interamericana de Derechos Humanos, serie C núm. 68, 16 de agosto de 20oo. Véase también la sentencia del caso Las Palmeras con Colombia, Corte Interamericana de Derechos Humanos, serie C núm. 9o, 6 de diciembre de 2001. 
jugar un rol fundamental. A modo de ejemplo, desde comienzos de la década de 1990, la Comisión se ha referido a la incompatibilidad de las leyes de amnistía aprobadas en Argentina ${ }^{11} \mathrm{y}$ Uruguay ${ }^{12}$ con las obligaciones de investigar y sancionar graves violaciones a derechos humanos. En su Informe anual de 1996, la CIDH reiteró dicha posición, en relación con la Ley de Amnistía de Guatemala (CIDH, 1996: cap. 5), e hizo lo propio respecto de cada uno de los países que adoptaron leyes de amnistía a lo largo de los años noventa en América Latina. ${ }^{13}$

Otros ejemplos de estándares confeccionados en el SIDH en que la CIDH tuvo la primicia pueden ser observados en un informe temático sobre la incompatibilidad de las leyes de desacato con el derecho a la libertad de expresión $;{ }^{14} \mathrm{o}$ en informes finales sobre el fondo que establecieron la obligación de demarcar, titular y sanear territorios indígenas; ${ }^{15}$ etcétera.

Finalmente, entre la gran variedad de decisiones de los órganos del SIDH con un impacto acentuado, podemos mencionar, a modo de ejemplo, las que establecen las siguientes obligaciones estatales:

- La prohibición de la colegiación profesional obligatoria para periodistas. ${ }^{16}$

- La obtención obligatoria del consentimiento de pueblos indígenas o tribales frente a proyectos de desarrollo a gran escala. ${ }^{17}$

11. Casos 10.147, 10.181, 10.240, 10.262, 10.309 y 10.311 con Argentina, Comisión Interamericana de Derechos Humanos, Informe 28/92, 2 de octubre de 1992.

12. Casos 10.029, 10.036, 10.145, 10.305, 10.372, 10.373, 10.374 y 10.375 con Uruguay, Comisión Interamericana de Derechos Humanos, Informe 29/92, 2 de octubre de 1992.

13. Para un análisis sobre los antecedentes de la CIDH sobre la obligación de dejar sin efecto leyes internas contrarias a la obligación de investigar y sancionar graves violaciones de derechos humanos, véase CIDH (2013: 72-86).

14. En 1995, la CIDH publicó un informe temático sobre el particular, adelantándose en tiempo y en la profundidad del análisis con relación a la primera sentencia de la Corte IDH relacionada con la colisión entre el tipo penal de desacato y el derecho a la libertad de expresión: caso Palamara Iribarne con Chile. Véase CIDH (1995) y sentencia del caso Palamara Iribarne con Chile, Corte Interamericana de Derechos Humanos, Serie C núm. 135, 22 de noviembre de 2005.

15. Resolución 12/85, Pueblo Yanomami con Brasil, Comisión Interamericana de Derechos Humanos, 5 de marzo de 1985, la cual aborda la obligación del Estado brasileño de demarcar, titular y proteger el territorio del pueblo indígena yanomami, obligación que sería ampliada con un mayor grado de detalle décadas más tarde en la sentencia del caso Comunidad Mayagna (Sumo) Awas Tingni con Nicaragua, Corte Interamericana de Derechos Humanos, serie C núm. 79, 31 de agosto de 2001.

16. «La colegiación obligatoria de periodistas (artículos 13 y 29 Convención Americana sobre Derechos Humanos)», Corte Interamericana de Derechos Humanos, serie A núm. 5, Opinión Consultiva OC-5/85, 13 de noviembre de 1985.

17. Sentencia del caso Pueblo Saramaka con Suriname, Corte Interamericana de Derechos Humanos, serie C núm. 172, excepción preliminar, fondo, reparaciones y costas, 28 de noviembre de 2007. 
- La obligación de investigar ciertas violaciones de derechos humanos a través de tipos penales específicos, como tortura, en casos de violencia sexual ejercida en el marco de interrogatorios u operativos policiales o militares. ${ }^{18}$

- El empleo de una debida diligencia reforzada para investigar y prevenir la violencia contra la mujer ${ }^{19}$ debiendo las autoridades competentes seguir lo establecido en el Manual de Investigación y Documentación Efectiva sobre Tortura, Castigos y Tratamientos Crueles, Inhumanos o Degradantes (Protocolo de Estambul) y en los Guidelines for Medical-legal Care for Victims of Sexual Violence de la Organización Mundial de la Salud. ${ }^{20}$

- La prohibición de la imposición obligatoria de la pena de muerte en casos de sentencias condenatorias para ciertos delitos o su aplicación al margen de las garantías de un debido proceso (CIDH, 2011b).

- La inconvencionalidad de la prohibición de la fecundación in vitro. ${ }^{21}$

- Una variedad de obligaciones positivas vinculadas al acceso a la información en asuntos de interés público. ${ }^{22}$

- Ciertas obligaciones de acceso a derechos en condiciones de igualdad a las parejas del mismo sexo. ${ }^{23}$

18. Caso 10.970, Raquel Martín de Mejía con Perú, Comisión Interamericana de Derechos Humanos, Informe 5/96, 1 de marzo de 1996, sección B, el cual antecede en varios años el primer caso en el que la Corte IDH ponderó la calificación jurídica de la violencia sexual bajo la categoría de tortura. Al respecto, véase sentencia del caso Penal Miguel Castro Castro con Perú, Corte Interamericana de Derechos Humanos, serie C núm. 160, 25 de noviembre de 2006.

19. Véanse, por ejemplo, la sentencia del caso González y otras (Campo Algodonero) con México, Corte Interamericana de Derechos Humanos, serie C núm. 160, excepción preliminar, fondo, reparaciones y costas, 16 de noviembre de 2009; y sentencia del caso J. con Perú, Corte Interamericana de Derechos Humanos, serie C núm. 275, excepción preliminar, fondo, reparaciones y costas, 27 de noviembre de 2013.

20. Sentencia del caso Favela Nova Brasilia con Brasil, Corte Interamericana de Derechos Humanos, serie C núm. 333, excepciones preliminares, fondo, reparaciones y costas, 16 de febrero de 2017, foja 255.

21. Sentencia del caso Artavia Murillo y otros (Fecundación in Vitro) con Costa Rica, Corte Interamericana de Derechos Humanos, serie C núm. 257, excepciones preliminares, fondo, reparaciones y costas, 28 de noviembre de 2012.

22. Sentencia del caso Claude Reyes y otros con Chile, Corte Interamericana de Derechos Humanos, serie C núm. 151, 19 de septiembre de 2006.

23. "Identidad de género e igualdad y no discriminación a parejas del mismo sexo: Obligaciones estatales en relación con el cambio de nombre, la identidad de género, y los derechos derivados de un vínculo entre parejas del mismo sexo (interpretación y alcance de los artículos 1.1, 3, 7, 11.2, 13, 17, 18 y 24 , en relación con el artículo 1 de la Convención Americana sobre Derechos Humanos)», Corte Interamericana de Derechos Humanos, serie A, núm. 24, Opinión Consultiva OC-24/17, 24 de noviembre de 2017. 
- Garantías judiciales específicas a los procedimientos de determinación de la condición de persona refugiada y apátrida (CIDH, 2020).

\section{Intensidad moderada}

Se ubican en esta categoría las decisiones que reafirman un estándar exigible a los Estados que conforman el SIDH o expanden su fuente normativa. Podemos mencionar como ejemplo los extremos de la sentencia en el caso Saramaka con Surinam, en que la Corte IDH se adhirió a los estándares previstos en el Convenio 169 de la Organización Internacional del Trabajo (OIT), y que ya habían sido desarrollados en pronunciamientos del sistema universal y en informes de fondo de la $\mathrm{CIDH},{ }^{24}$ sobre el derecho a la consulta previa, libre e informada de los pueblos indígenas y tribales. ${ }^{25}$

Tal como fue mencionado en la sección anterior, el componente de Saramaka que establece la obligatoriedad de obtención del consentimiento del pueblo o comunidad frente a proyectos de inversión a gran escala constituye una decisión con un impacto acentuado, pues se trata de un estándar creado por la Corte IDH que pasó a integrar el derecho interamericano y ser exigible a los Estados parte de la CADH. Ahora bien, los estándares sobre el derecho a la consulta previa, libre e informada en dicha sentencia reproducen los que ya habían sido desarrollados por otros organismos supranacionales de derechos humanos, y ya se encontraban plasmados en el principal instrumento de derecho duro sobre la materia, el Convenio 169 de la OIT.

Sin duda, la adhesión a los estándares derivados de otras fuentes del derecho internacional de derechos humanos confiere una mayor visibilidad a las obligaciones asumidas por los Estados que integran el SIDH. Sin embargo, la exigibilidad de la obligación de realizar procesos de consulta previa, libre e informada a pueblos y comunidades indígenas y tribales ya se encontraba vigente en otros instrumentos, declaraciones y pronunciamientos de organismos que, en su totalidad, conformaban el corpus iuris internacional ${ }^{26}$ antes de la sentencia del caso Saramaka. Al igual

24. Véase, por ejemplo, caso 12.053, Comunidades Indígenas Mayas del Distrito de Toledo, Comisión Interamericana de Derechos Humanos, Informe 40/04, 12 de octubre de 2004, el cual antecede la sentencia del caso Saramaka con Suriname, de 2007 , en la reafirmación de las obligaciones de consultar a los pueblos indígenas y tribales previo a toda decisión susceptible de afectar sus derechos, reconocidas en el Convenio 169 de la OIT y en pronunciamientos de órganos de tratado del sistema universal.

25. Sentencia del caso Pueblo Saramaka con Suriname, Corte Interamericana de Derechos Humanos, serie C núm. 172, excepción preliminar, fondo, reparaciones y costas, 28 de noviembre de 2007.

26. La expresión corpus iuris internacional fue utilizada por primera vez por la Corte IDH en la Opinión Consultiva OC-16/99 y puede ser definida como «el conjunto de instrumentos jurídicos internacionales (tratados, convenios, resoluciones y declaraciones) susceptibles de ser interpretados y aplicados para darle coherencia y armonía al contenido de una norma vinculante en la jurisdicción supranacional». Véase Yáñez (2021: 18), donde se cita a Jorge Rivero Evia, «Corpus iuris internacional», Enciclopedia Jurídica Online, 2015, disponible en https://bit.ly/3 $\mathrm{H}_{3} 6 \mathrm{cO}$. 
que había hecho la CIDH en el caso de las Comunidades Indígenas Mayas del Distrito de Toledo, con relación a la Declaración Americana, ${ }^{27}$ la sentencia sobre el caso Saramaka interpretó el artículo 21 de la $\mathrm{CADH}$, en lo que se refiere al derecho de propiedad colectiva de los pueblos indígenas y tribales, a la luz del corpus iuris internacional sobre la consulta previa, libre e informada entonces vigente. Al deslindar la obligación de realizar procesos de consulta previa directamente de la $\mathrm{CADH}$, la Corte IDH estableció un blindaje adicional de protección del derecho de los pueblos indígenas y tribales, lo cual posee una particular repercusión para los países que no han ratificado el principal tratado sobre la materia, el Convenio 169 de la OIT - por ejemplo, Surinam, Panamá y todos los países caribeños, a excepción de Dominica一, bien como para aquellos países en donde gobiernos o frentes parlamentarios pudiesen promover la denuncia del referido convenio.

Dos ejemplos de esta última situación se han dado en Chile (Agüero, 2020: 18-19) $y$, más recientemente, en Brasil. ${ }^{28}$ Congresistas e integrantes de los gobiernos de ambos países han defendido la denuncia del Convenio 169 de la OIT, bajo el argumento de que las exigencias allí establecidas generan obstáculos a proyectos de desarrollo e inseguridad para la inversión privada en territorios indígenas. A la luz de los parámetros del caso Saramaka, ampliados en fallos posteriores, ${ }^{29}$ la denuncia del Convenio 169 sería inocua frente a la obligación consultar previamente a los pueblos indígenas, pues esta se deriva, igual y directamente, de la $\mathrm{CADH}$, del artículo 1 común a los Pactos de Derechos Civiles y Políticos y de Derechos Económicos, Sociales y Culturales, entre otros instrumentos (Yáñez, 2021: 18).

En conclusión, el extremo de la decisión relacionada con la obligación de consultar en el caso Saramaka no llega a crear un estándar jurídico nuevo, sino que reitera un estándar existente y lo enmarca como criterio interpretativo de una determinada disposición de la CADH. La exigibilidad y el alcance de la obligación internacional siguen incólumes, pero su fuente normativa es ampliada. Estos son los elementos de lo que aquí categorizamos como impacto con intensidad moderada. Son varias las

27. Caso 12.053, Comunidades Indígenas Mayas del Distrito de Toledo, Comisión Interamericana de Derechos Humanos, el cual establece que la obligación de realizar procesos de consulta previa, libre e informada se encuentra protegido bajo el derecho de propiedad colectiva de los pueblos indígenas, a la luz del artículo 23 de la Declaración Americana.

28. «CIDH expresa preocupación ante proyectos de ley en Brasil que podrían constituir retrocesos en materia de derechos humanos de los pueblos indígenas», Organización de los Estados Americanos, 9 de septiembre de 2021, disponible en https://bit.ly/3HeIpot.

29. Véanse, por ejemplo, la sentencia del caso Pueblos Indígenas Kuna de Madungandí y Emberá de Bayano y sus miembros con Panamá, Corte Interamericana de Derechos Humanos, serie C núm. 284, excepciones preliminares, fondo, reparaciones y costas, 14 de octubre de 2014, foja 116; y sentencia del caso Pueblos Kaliña y Lokono con Surinam, Corte Interamericana de Derechos Humanos, serie C núm. 309, excepciones preliminares, fondo, reparaciones y costas, 25 de noviembre de 2015, fojas 122-124. 
decisiones de los órganos del SIDH que proyectan ese tipo de impacto, por lo que haremos una mención lacónica, a modo de ejemplo, a aquellas que recogen los estándares del Comité de los Derechos del Niño de la ONU sobre el derecho a la identidad y las obligaciones estatales frente a los hijos y las hijas de víctimas de desaparición forzada $;^{30} \mathrm{y}$ las que establecen obligaciones específicas de prevención en el marco de operativos militares, a la luz de las prohibiciones a ciertos medios de guerra, derivados del derecho internacional humanitario. ${ }^{31}$ En ambos ejemplos, la Corte IDH interpreta disposiciones de la CADH a la luz de estándares contenidos en otras fuentes del derecho internacional de derechos humanos, sin que cree en sí un nuevo parámetro de actuación estatal.

Cabe aquí matizar aquellas situaciones en que la Corte IDH reproduce estándares jurídicos preexistentes, pero sus medidas de reparación son más favorables a las víctimas, en comparación con decisiones relacionadas con supuestos fácticos idénticos o conexos. Es el caso, por ejemplo, de los fallos recientes sobre la justiciabilidad directa del derecho a la salud, ${ }^{32}$ como el caso Cuscul Pivaral y otros con Guatemala, ${ }^{33}$ o sobre la reparación de la violación de ciertos derechos de naturaleza ambiental, económica y cultural, en el caso Lhaka Honhat con Argentina. ${ }^{34}$

Nuevamente, tales decisiones no crean un estándar jurídico u obligación que no estuviesen ya contempladas en otras fuentes normativas, pero además de interpretar la $\mathrm{CADH}$ a la luz de estándares preexistentes, disponen medidas de reparación más favorables a las víctimas y establecen criterios un poco más precisos para distinguir las obligaciones de carácter progresivo de aquellas de naturaleza inmediata - por ejemplo, con relación al acceso a un tratamiento médico bajo condiciones mínimas de disponibilidad y accesibilidad para personas con VIH/sida, en el caso Cuscul Piva-

30. Véanse la sentencia del caso Contreras y otros con El Salvador, Corte Interamericana de Derechos Humanos, serie C núm. 232, fondo, reparaciones y costas, 31 de agosto de 2011; y sentencia del caso Gelman con Uruguay, Corte Interamericana de Derechos Humanos, serie C núm. 221, fondo y reparaciones, 24 de febrero de 2011.

31. Véanse la sentencia del caso Masacre de Santo Domingo con Colombia, Corte Interamericana de Derechos Humanos, serie C núm. 259, excepciones preliminares, fondo y reparaciones, 30 de noviembre de 2012; y sentencia del caso Cruz Sánchez y otros con Perú, Corte Interamericana de Derechos Humanos Excepciones, serie C núm. 292, excepciones preliminares, fondo, reparaciones y costas, 17 de abril de 2015.

32. Juan Jesús Góngora, «La Corte Interamericana y los derechos económicos, sociales, culturales y ambientales: Las virtudes del caso Cuscul Pivaral y otros vs. Guatemala», Justicia en las Américas, 31 de octubre de 2018, disponible en https://bit.ly/3JawqCV.

33. Sentencia del caso Cuscul Pivaral y otros con Guatemala, Corte Interamericana de Derechos Humanos, serie C núm. 359, excepción preliminar, fondo, reparaciones y costas, 23 de agosto de 2018.

34. Ángel Cabrera, Daniel Cerqueira y Salvador Herencia, «Comentarios a la sentencia de la Corte Interamericana sobre el caso Lhaka Honhat vs. Argentina», Justicia en las Américas, 30 de abril de 2020, disponible en https://bit.ly/3EBErxf. 
ral y otros-. Lo anterior implica no solo la ampliación de una regla de adjudicación de la Corte IDH - violación directa del derecho a la salud bajo el artículo 26 de la $\mathrm{CADH}$, por ejemplo-, sino un nuevo parámetro de remediación por la violación de derechos económicos, sociales, culturales y ambientales. En ese sentido, los extremos de las decisiones comentadas en el párrafo anterior que amplían las obligaciones estatales en materia de reparación o que precisan el contenido de algunas obligaciones estatales con relación al derecho a la salud, constituyen, genuinamente, un nuevo estándar jurídico, por lo que podrían ser catalogadas como decisiones de impacto acentuado.

\section{Baja intensidad}

En esta categoría incluimos aquellas decisiones que reproducen estándares reconocidos por los propios órganos del SIDH o derivados de otras fuentes del derecho internacional de los derechos humanos, pero que reducen el alcance de las obligaciones estatales en materia de reparación. Algunos fallos recientes de la Corte IDH sobre el derecho a la estabilidad laboral y a la seguridad social se ubican en esta categoría. Antes de profundizar en el análisis de algunos de ellos, describiremos brevemente la evolución de la jurisprudencia interamericana con relación a la justiciabilidad de los derechos económicos, sociales, culturales y ambientales.

En los últimos cuatro años, la Corte IDH ha emitido varias sentencias que reconocen la justiciabilidad directa del artículo 26 de la $\mathrm{CADH}$, referido a estos derechos. Tales fallos detallan las obligaciones estatales frente a derechos como la salud, trabajo, estabilidad laboral, seguridad social, medioambiente sano, entre otros, en gran medida, a partir de diversas fuentes del derecho internacional de los derechos humanos, incluyendo convenciones de la OIT y pronunciamientos del sistema universal. El principal giro jurisprudencial sobre la competencia contenciosa de la Corte IDH en torno al artículo 26 de la CADH ocurrió en agosto de 2017, con la sentencia del caso Lagos del Campo con Perú, ${ }^{35}$ primer fallo que declaró la violación directa de un derecho social, hasta entonces considerado justiciable de manera indirecta o por conexidad, bajo ciertos derechos civiles y políticos protegidos en la CADH (Melish, 2003: cap. 3).

Lo más cercano a la justiciabilidad directa de los derechos económicos, sociales, culturales y ambientales en la jurisprudencia del tribunal interamericano había ocurrido en la sentencia del caso Acevedo Buendía con Perú, de julio de 2009, en que la mayoría de sus integrantes descartó la violación del artículo 26 de la $\mathrm{CADH}$, pero sostuvo que la prohibición de regresividad es una obligación justiciable. Lagos

35. Sentencia del caso Lagos del Campo con Perú, Corte Interamericana de Derechos Humanos, serie C núm. 340, excepciones preliminares, fondo, reparaciones y costas, 31 de agosto de 2017. 
del Campo sobrepasa esta posición y reconoce la justiciabilidad del artículo 26 de la $\mathrm{CADH}$, más allá de los supuestos de no regresividad e incumplimiento de obligaciones inmediatas.

No viene al caso revisitar los vacíos argumentativos de la referida sentencia, ${ }^{36}$ pero a los fines del examen de intensidad de su impacto, Lagos del Campo se limita a reiterar, bajo el manto argumentativo del corpus iuris internacional, los estándares del sistema universal, convenios y pronunciamientos de comités de la OIT. Es decir, si bien innova al momento de declarar la existencia de un derecho social autónomo y justiciable, las obligaciones estatales reconocidas replican las que emanan de otras fuentes normativas. En principio, ese tipo de decisión se ubicaría en la categoría de impacto moderado, pero tanto Lagos del Campo como otras sentencias conexas disponen reparaciones más acotadas que en precedentes que comparten los mismos marcos fácticos, entonces decididos bajo la jurisprudencia basada en la conexidad de los derechos económicos, sociales, culturales y ambientales con derechos civiles y políticos.

A modo de ejemplo, en la sentencia del caso Canales Huapaya y otros con Perú, ${ }^{37}$ de junio de 2015, relacionada con el cese arbitrario de trabajadores del Congreso peruano en la primera mitad de la década de 1990, la Corte IDH había dispuesto el pago de una indemnización compensatoria, debido a la imposibilidad de reponer todos los beneficios sociales no devengados de las víctimas. En cambio, en los casos más recientes en que se ha declarado la violación directa del derecho a la estabilidad laboral bajo el artículo 26 de la CADH, el tribunal interamericano se abstuvo de ordenar la reposición laboral de las víctimas, estableció compensaciones mucho más frugales y, en algunos casos, rechazó las medidas de no repetición solicitadas por la CIDH y los representantes de las víctimas (Serrano, 2020: 139-141). Lo anterior, pese a que, sobre todo en los casos peruanos, las controversias decididas se enmarcaban en un contexto reiterado de vulneración de derechos laborales, caracterizados por el cese masivo de empleados públicos y privados y la ausencia de una protección judicial efectiva, a lo largo de la década de 1990.

En el caso San Miguel Sosa y otras con Venezuela, varias funcionarias del Estado fueron desvinculadas de la función pública de forma arbitraria y discriminatoria, en represalia contra sus opiniones políticas. ${ }^{38}$ Nuevamente, la Corte IDH reconoció el derecho autónomo a la estabilidad laboral bajo el artículo 26 de la $\mathrm{CADH}$, pero se

36. Daniel Cerqueira, «La justiciabilidad de los DESCA bajo la Convención Americana», Justicia en las Américas, 29 de mayo de 2018, disponible en https://bit.ly/32Hb9Qt.

37. Sentencia del caso Canales Huapaya y otros con Perú, Corte Interamericana de Derechos Humanos, serie C núm. 296, excepciones preliminares, fondo, reparaciones y costas, 24 de junio de 2015.

38. Sentencia del caso San Miguel Sosa y otras con Venezuela, Corte Interamericana de Derechos Humanos, serie C núm. 348, fondo, reparaciones y costas, 8 de febrero de 2018. 
abstuvo de ordenar la reposición laboral de las víctimas o el pago de una compensación adicional, por concepto de liquidación de beneficios sociales no habidos, como había hecho en varios casos anteriores que siguieron la línea jurisprudencial pre $\mathrm{La}$ gos del Campo. La Corte tampoco dispuso medidas de no repetición, pese al contexto generalizado, vigente hasta la fecha, de persecución generalizada a servidores públicos que manifestaban posiciones críticas al gobierno en Venezuela.

Esta ambivalencia entre vanguardismo en el reconocimiento de derechos sociales autónomos y justiciables frente a medidas de reparación más acotadas es aún más notable con relación a las últimas dos sentencias relacionadas con el derecho a la seguridad social. El caso ANCEJUB-SUNAT con Perú es particularmente representativo de esta tendencia, pues amplía el catálogo de derechos violados frente al incumplimiento de sentencias judiciales que amparan el derecho pensionario de extrabajadores del sector público en Perú, a partir del derecho a la seguridad social (artículo 26 de la $\mathrm{CADH}$ ), y del impacto del incumplimiento de tales sentencias en las condiciones de vida de las víctimas, en el marco del artículo 4.1 de la $\mathrm{CADH}$, interpretado a partir del derecho a una vida digna. ${ }^{39}$

Pese a ese giro jurisprudencial, en teoría más garantista para las víctimas, los estándares que fundamentan las obligaciones estatales en torno a la seguridad social son, en esencia, una reproducción de pronunciamientos de la OIT y del sistema universal y replican los estándares que ya habían fundamentado decisiones anteriores sobre los mismos supuestos fácticos, como es el caso Muelle Flores con Perú, de $2019 .{ }^{40}$ Por otro lado, las medidas de reparación son considerablemente más acotadas que las de casos anteriores, relativos a supuestos fácticos conexos o idénticos, en que la Corte IDH se limitó a declarar la violación de derechos civiles y políticos (artículos 8, 25 y 21 de la CADH). Entre los casos sobre la afectación del derecho a la seguridad social en Perú decididos bajo la lógica de la conexidad entre derechos económicos, sociales, culturales y ambientales y derechos civiles y políticos, pero cuyas reparaciones fueron más favorables a las víctimas, podemos citar Acevedo Jaramillo y otros 41 y Acevedo Buendía y otros (Cesantes y Jubilados de la Contraloría), ${ }^{42}$ ambos referidos al incumplimiento de sentencias que ordenaban la reposición de

39. Sentencia del caso Asociación Nacional de Cesantes y Jubilados de la Superintendencia Nacional de Administración Tributaria (ANCEJUB-SUNAT) con Perú, Corte Interamericana de Derechos Humanos, serie C núm. 349, excepciones preliminares, fondo, reparaciones y costas, 21 de noviembre de 2019.

40. Sentencia del caso Muelle Flores con Perú, Corte Interamericana de Derechos Humanos, serie C núm. 375, excepciones preliminares, fondo, reparaciones y costas, 6 de marzo de 2019.

41. Sentencia del caso Acevedo Jaramillo y otros con Perú, Corte Interamericana de Derechos Humanos, serie C núm. 144, 7 de febrero de 2006.

42. Sentencia del caso Acevedo Buendía y otros (Cesantes y Jubilados de la Contraloría) con Perú, Corte Interamericana de Derechos Humanos, serie C núm. 198, excepción preliminar, fondo, reparaciones y costas, 1 de junio de 2009 . 
regímenes previsionales más favorables para exfuncionarios del sector público en Perú. ${ }^{43}$

Ahora bien, es necesario aclarar que las consideraciones de esta sección no pretenden generalizar la baja intensidad del impacto jurídico de las decisiones recientes de la Corte IDH en materia de derechos económicos, sociales, culturales y ambientales. Como se mencionó en la sección anterior, varios fallos, sobre todo relativos al derecho a la salud y a derechos naturaleza ambiental de los pueblos indígenas, además de «interamericanizar» los estándares de otros sistemas supranacionales, amplían algunos aspectos de las obligaciones estatales en materia de reparación. En los casos Poblete Vilches con Chile ${ }^{44}$ y Cuscul Pivaral con Guatemala, en particular, las medidas de no repetición incluyen directrices claras para el diseño de políticas públicas y obligaciones bastante detalladas que cobran sentido a las conclusiones sobre la violación autónoma del derecho a la salud bajo el artículo 26 de la CADH.

En cualquier caso, sobran elementos para concluir que las sentencias dictadas en los últimos cuatro años con relación al derecho a la estabilidad laboral y a la seguridad social, aquí comentadas, buscan ampliar el catálogo de derechos convencionales violados bajo ciertos supuestos fácticos, sin que ello deslinde en la ampliación de las obligaciones estatales en materia de reparación. Bajo los criterios de impacto adoptados en el presente artículo, tales decisiones constituyen avances jurisprudenciales más retóricos que reales para las víctimas en particular y para el derecho interamericano en general.

\section{Consideraciones finales}

Sin pretender ser una categorización cartesiana del impacto de las decisiones de los órganos del SIDH, este artículo busca incentivar la adopción de una metodología más objetiva que permita distinguir avances jurisprudenciales genuinamente más favorable a las personas, derivados de decisiones de la CIDH y de la Corte IDH, de aquellas decisiones que se limitan a ampliar el catálogo de derechos convencionales violados. La metodología aquí empleada busca evidenciar, entre otras, el hecho de que algunas de decisiones que han sido catalogadas como históricas, inéditas o como un divisor de aguas por los propios órganos del SIDH, se limitan a reclasificar las disposiciones de la $\mathrm{CADH}$ declaradas en violación, sin que tengan la entidad para modificar el alcance de las obligaciones estatales aplicables a la controversia decidida o, en algunos casos, implican un retroceso en las obligaciones de los Estados en materia de reparación.

43. Daniel Cerqueira, «Jurisprudencia de la Corte IDH en casos sobre DESCA: Entre lo retórico y lo impredecible», Justicia en las Américas, 7 de enero de 2020, disponible en https://bit.ly/3pnU $72 \mathrm{~F}$.

44. Sentencia del caso Poblete Vilches y otros con Chile, Corte Interamericana de Derechos Humanos, serie C núm. 349, fondo, reparaciones y costas, 8 de marzo de 2018. 
En un sistema caracterizado por un bajo grado de cumplimiento de las medidas de reparación dictadas en informes finales sobre el fondo por parte de la CIDH y en sentencias emitidas por la Corte IDH, nos parece que el punto de partida de la discusión sobre el impacto del SIDH debe ser la comprensión de la eficacia del derecho interamericano a partir de la capacidad de sus órganos de generar un consenso mínimo sobre el alcance de las obligaciones estatales. Lo anterior, a los fines de que los operadores jurídicos y órganos de los Estados cuenten con parámetros jurídicos inequívocos que les permitan integrar las reglas y principios del derecho interamericano a las normas, prácticas jurisprudenciales y políticas públicas en el ámbito doméstico.

Aunque somos conscientes de que este artículo no está exento de simplificaciones analíticas, esperamos que estimule un abordaje más crítico y menos autorreferencial al momento de evaluarse si una determinada decisión implica un avance jurisprudencial genuino, en tanto amplía las obligaciones estatales aplicables a ciertos supuestos fácticos.

\section{Referencias}

AgÜERo, Felipe (2020). «Un intento tempranamente frustrado de denunciar el Convenio 169 de la OIT en Chile». Aportes, 22: 18-19. Disponible en https://bit. ly $/ 3 \mathrm{Hd}_{2}$ Yub.

BASCH, Fernando, Leonardo Filippini, Ana Laya, Mariano Nino, Felicitas Rossi y Bárbara Schreiber (2010). «La efectividad del sistema interamericano de protección de derechos humanos: Un enfoque cuantitativo sobre su funcionamiento y sobre el cumplimiento de sus decisiones». Sur, 7 (12): 9-35. Disponible en https://bit. ly/3HoMsHF.

CIDH, Comisión Interamericana de Derechos Humanos (1995). Informe sobre la compatibilidad entre las leyes de desacato y la Convención Americana sobre Derechos Humanos. OEA/Ser. L/V/II.88, doc. 9 rev. Washington D. C. Disponible en https://bit.ly/3JpZt5w.

-. (1996). Informe anual de 1996. OEA/Ser.L/V/II.95. Doc. 7 rev. Washington D. C. Disponible en https://bit.ly/3JeRtnJ.

-. (2011a). Plan estratégico 2011-2015. Washington D. C. Disponible en https://bit. ly/3msmhYc.

-. (2011b). La pena de muerte en el sistema interamericano de derechos humanos: De restricciones a abolición. OEA/Ser.L/V/II. Doc. 68. Washington D. C. Disponible en https://bit.ly/3 $3 \mathrm{H}_{5} \mathrm{UswX}_{\text {. }}$

-. (2013). Informe anual de 2013. OEA/Ser.L/V/II. Doc. 50 Corr. 1. Washington D. C. Disponible en https://bit.ly/3qli8Sp.

-. (2017). Plan estratégico 2017-2022. OEA/Ser.L/V/II.161 Doc. 27/17. Washington D. C. Disponible en https://bit.ly/3qkopT1. 
-. (2020). Debido proceso en los procedimientos para la determinación de la condición de persona refugiada, y apátrida y el otorgamiento de protección complementaria. OEA/Ser.L/V/II. Doc. 255 Washington D. C. Disponible en https://bit.ly/3JfqkkA. Corte IDH, Corte Interamericana de Derechos Humanos (2018). Informe anual de 2018. San José. Disponible en https://bit.ly/32of8BB.

Corzo Sosa, Edgar (coordinador) (2013). Impacto de las sentencias de la Corte Interamericana de Derechos Humanos. Ciudad de México: Tirant lo Blanch, UNAM, IIJ.

DPLF, Fundación para el Debido Proceso Legal (2009). Digesto de jurisprudencia latinoamericana sobre crímenes de derecho internacional. Washington D. C. Disponible en https://bit.ly/3sq25dw.

Hart, Herbert L. A. (1961). The concept of law. Nueva York: Oxford University Press. Howse, Robert y Ruti Teitel (2010). «Beyond compliance: Rethinking why international law really matters». Global Policy, 1 (2): 127-136. DOI: 10.1111/j.1758-5899.2010.00035.x.

Kelsen, Hans (1967). Pure theory of law. Berkeley: University of California Press.

KrSTICEVIC, Viviana (2016). «La implementación de las decisiones del SIDH y la administración de justicia: Sinergias, tensiones y posibilidades». En Viviana Krsticevic, Alejandra Vicente y Antonio Jaén (coordinadores), Implementación de las Decisiones del Sistema Interamericano de Derechos Humanos: Aportes para la administración de la justicia (pp. 9-26). Washington D. C.: CEJIL. Disponible en https://bit.ly/3H5vn5a.

Melish, Tara (2003). La protección de los derechos económicos, sociales y culturales en el sistema interamericano de derechos humanos: Manual para la presentación de casos. New Haven: Orville H. Schell, Jr. Center for International Human Rights, Yale Law School.

Open Society Justice Initiative (2010). From judgment to justice: Implementing international and regional rights decisions. Nueva York. Disponible en https://bit. ly/3mQmxkj.

PARra, Óscar (2012). «La jurisprudencia de la Corte Interamericana respecto a la lucha contra la impunidad: Algunos avances y debates». Revista Jurídica de la Universidad de Palermo, 13 (1): 5-51. Disponible en https://bit.ly/3/heR3M.

Pozzolo, Susanna (1998). «Neoconstitucionalismo y especificidad de la interpretación constitucional». Doxa, 2 (21): 339-353. DOI: 10.14198/DOXA1998.21.2.25.

RAMíREZ, Manuel Quinche (2009). Los estándares de la Corte Interamericana y la Ley de Justicia y Paz. Bogotá: Universidad del Rosario.

Raustiala, Kal y Anne-Marie Slaughter (2002). «International law, international relations and compliance». En Walter Carlsnaes, Thomas Risse y Beth A. Simmons (editores), Handbook of international relations. Landres: SAGE. 
SÁncheZ, Camilo (2021). «Una década de peticiones y casos ante la CIDH». Aportes, 23: 28-30. Disponible en https://bit.ly/3qjnRwY.

Serrano, Silvia (2020). «Comentarios sobre el giro jurisprudencial de la Corte Interamericana en materia de justiciabilidad de los derechos económicos, sociales, culturales y ambientes a la luz de seis sentencias emitidas entre 2017 y 2019». En Mariela Morales (coordinadora), Interamericanización de los DESCA: El caso Cuscul Pivaral de la Corte IDH (pp. 95-152). Querétaro: Instituto Max Planck de Derecho Público Comparado y Derecho Internacional Público.

Soтo MuÑoz, Daniel (2017). «Influencia del derecho internacional en la reforma de la justicia militar en Latinoamérica». Política y Estrategia, 118: 160-198. DOI: 10.26797/rpye.voi118.125.

YÁñEZ, Nancy (2021). «El uso de fuentes del derecho internacional en las decisiones de la Corte Interamericana de Derechos Humanos respecto a los derechos de los pueblos indígenas». Aportes, 23: 18-20. Disponible en https://bit.ly/3qjnRwY.

\section{Sobre el autor}

Daniel Cerqueira es abogado de la Universidade Federal de Minas Gerais, Brasil. Licenciado en Relaciones Internacionales de la Pontifícia Universidade Católica de Minas Gerais, Brasil. LLM en Estudios Legales Internacionales de la Universidad de Georgetown, Estados Unidos. Director del Programa Derechos Humanos y Recursos Naturales de la Fundación para el Debido Proceso (Due Process of Law Foundation). Entre 2006 y 2013 se desempeñó como abogado de la Comisión Interamericana de Derechos Humanos. Su correo electrónico es dcerqueira@dplf.org. (D) https://orcid. org/0000-0001-8205-1976. 
